PALAVRAS. Revista de Epistemología, Metodología y Ética del Psicoanálisis

ISSN: 2468-9831

www.revistas.unlp.edu.ar/palavras

palavras@outlook.com.ar

Argentina

\title{
LA "SEXUALIDAD INFANTIL" SEGÚN FREUD: GENEALOGÍA DEL CONCEPTO, OPERACIONES Y ARQUEOLOGÍA DEL PSICOANÁLISIS
}

DOI $10.24215 / 24689831 \mathrm{e} 011$

Diego Tolini

\begin{abstract}
This paper examines the Freudian problem of the infantile sexuality from the perspective of certain contributions that the French thought has provided since the 1960s in the attempt to link the psychoanalysis with the problem of power. We will start by outlining three aspects of the Freudian problem of the infantile sexuality: the causal power that was assigned to it by Freud, the idea of a primary unconscious, and the question of the family. Foucault will allow us to link Freud's theory with certain discourse devices arose in the context of the disciplinary power; Deleuze and Guattari will provide an interpretation of the psychoanalytical operation giving emphasis to the problems of the representation, the transcendence and the meaning; and Derrida will question the psychoanalytical notion of the origin.
\end{abstract}

Key-words: sexuality - Freud - Foucault - Deleuze - Derrida
Este trabajo busca poner el problema freudiano de la sexualidad infantil bajo la perspectiva de ciertos aportes provenientes del campo de debate que, a partir de la década de 1960, comenzó a gestarse en Francia con vistas a vincular el psicoanálisis con la cuestión del poder. Partiremos de destacar tres aspectos surgidos de la elaboración freudiana del problema de la sexualidad infantil: la determinación causal que Freud le asignó, la idea de un inconsciente originario, y la cuestión de la familia. Foucault nos permitirá vincular la teoría de Freud con ciertos dispositivos discursivos surgidos en el marco del denominado poder disciplinario; Deleuze y Guattari brindarán una interpretación de la operación del psicoanálisis en la que destacan los problemas de la representación, la trascendencia y el sentido; y Derrida nos proporcionará la oportunidad de problematizar la noción psicoanalítica de origen.

Palabras clave: sexualidad - Freud - Foucault Deleuze - Derrida

\section{Cómo citar este artículo:}

Tolini, D. (2016). La "sexualidad infantil" según Freud: genealogía del concepto, operaciones y arqueología del psicoanálisis. Palavras. Revista de Epistemología, Metodología y Ética del Psicoanálisis, 2, 120-152. Recuperado de www.revistas.unlp.edu.ar/palavras 


\section{LA "SEXUALIDAD INFANTIL" SEGÚN FREUD: GENEALOGÍA DEL CONCEPTO, OPERACIONES Y ARQUEOLOGÍA DEL PSICOANÁLISIS}

\section{Diego Tolini *}

\section{Introducción}

Pretendemos aquí poner el problema de la sexualidad infantil, tal como fue desarrollado por Freud, principalmente en sus Tres ensayos sobre teoría sexual, bajo la perspectiva de algunos de los autores más influyentes del campo de debate del pensamiento francés de la segunda mitad del siglo XX: Foucault, Deleuze, Guattari y Derrida.

Los aportes de Foucault permitirán poner en cuestión la idea de que el siglo XVII habría dado inicio a una época de la represión sexual, y la noción de una naturaleza esencialmente negativa del poder. Este cuestionamiento partirá de la constatación de la gran proliferación discursiva que, desde el siglo referido hasta nuestros dias, habría surgido en torno a la cuestión del sexo. El psicoanálisis será ubicado, por el autor, en el contexto de dicha proliferación discursiva y del poder centrado en la vida que con ella se articula. En la perspectiva de Foucault, se trataria no tanto de una represión del sexo sino de una relación del mismo con la palabra con vistas a ejercer ciertos efectos sobre su economía. El campo discursivo entretejido en torno al sexo habría sido entonces efecto de, e instrumento para las relaciones de poder.

Deleuze y Guattari brindarán una interpretación de la operación y los efectos que el psicoanálisis habría buscado ejercer sobre el sexo. Introducirán, para tal efecto, la noción de "rizoma", la cuestión de la familia, y los problemas de la representación y la trascendencia, lo cual terminará por evidenciar, por un lado, la voluntad psicoanalítica de logicización de ese mundo de deseo parcial, múltiple y descodificado que constituyó el "descubrimiento" freudiano fundamental, y delimitar, por el otro, el plano del sentido como condición de posibilidad de la hermenéutica psicoanalítica.

\footnotetext{
* Facultad de Psicología de la Universidad de Belgrano, Argentina. Mail: diegotolini@gmail.com
} 
La perspectiva de Derrida nos proporcionará la oportunidad de problematizar la noción psicoanalítica de origen, para lo cual introducirá la noción batesoniana de "doble vínculo" y su idea de una "restancia del resto".

Para exponer estas cuestiones, empezaremos por destacar tres aspectos que se desprenden de la elaboración freudiana del problema de la sexualidad infantil.

\section{Tres aspectos del problema freudiano de la infantile Sexualität}

\section{2. a. El carácter determinante de la sexualidad infantil}

La pulsión sexual es, para Freud, originariamente perversa y parcial. A partir de la pubertad, los elementos fragmentarios de la pulsión sexual adoptarán una organización bajo el primado de la zona genital. Pero durante la infancia, al no ser aún determinante la influencia de la cultura, la sexualidad se presenta en su naturaleza espontánea, es decir, en su perversidad y parcialidad originarias. Así, cada pulsión sexual-infantil buscará su propia satisfacción perversa de manera anárquica, cada una de ellas ligada a fuentes orgánicas y a metas específicas.

Es por estas características innatas que la pulsión sexual predispone originaria y universalmente- a los individuos a la perversión. Pero el que esta disposición innata logre expresarse en la constitución sexual definitiva dependerá de las intensidades relativas de los componentes singulares de la pulsión sexual infantil, y del destino sufrido por ellos en el curso del desarrollo. Así, cuando dichos componentes se conservan en su proporción relativa y se desarrollan hasta fijarse en la vida sexual del individuo promoviendo prácticas que ocupan la parte central y a veces exclusiva de la misma, el resultado final será una vida sexual perversa. La perversión estaría aquí dada por la prevalencia de todos esos componentes de la sexualidad que no han logrado ingresar en aquella organización subordinada a lo genital y orientada a la conservación de la especie, meta última de lo sexual. 
Cuando, por el contrario, algunos componentes de la pulsión sexual infantil son reprimidos, la vida sexual del individuo se verá considerablemente restringida y se exteriorizará, de manera exclusiva o predominante, a través de los síntomas producto de la represión. Las trasgresiones y aberraciones propias de la vida sexual infantil fueron aquí, a diferencia del caso anterior, enviadas por la represión al inconsciente desde donde continúan buscando una satisfacción que sólo pueden alcanzar de manera sustitutiva a través de los sintomas: este es el caso de los neuróticos.

Cuando, por último, a las pulsiones perversas de la constitución originaria y universal se les procura drenaje y empleo en otros campos, es decir, cuando se sustituye su meta sexual por una meta no sexual, el resultado es un incremento considerable de la capacidad de rendimiento psíquico. En esto consiste el proceso de sublimación, y en él sitúa Freud una de las fuentes de la actividad artística y de gran parte de nuestras "virtudes". Este sería el caso más favorable y más próximo a la vida sexual normal ${ }^{1}$.

Tres serán entonces, para Freud, los destinos posibles de la disposición perversa original y universal: la perversión, la neurosis, o, por medio de la sublimación de la sexualidad, la vida normal o virtuosa, la vida que más contribuye a la perpetuación de la cultura. La tramitación de lo infantil, donde esta disposición hace su aparición originaria, define la subjetividad psicoanalítica. Así, la desviación de lo normal será producto de una nula o insuficiente tramitación de lo sexual-infantil, es decir, de la persistencia o invasión de lo infantil en la vida adulta, o, como dice Freud, de una inhibición del desarrollo, de su regresión a una fase anterior.

Es fundamental, para Freud, limitar el alcance del desenfreno sexual infantil, y esto en virtud del "vínculo de oposición que existe entre la cultura y el libre desarrollo de la sexualidad" (Freud, 1905/2008: 221). En efecto, la infancia, librada al devenir espontáneo y desregulado de su sexualidad, es amenazante para el orden cultural: de aquí la importancia adaptativa de la

\footnotetext{
1 Esta expresión ("vida sexual normal") es problemática pues es sabido que Freud demostró la dificultad, cuando no la imposibilidad, de emplear el criterio de normalidad cuando se trata de lo sexual. Sin embargo, es posible comprobar que su obra se encuentra atravesada por el régimen de lo normal-anormal: esto fue algo sobre lo que Foucault hizo hincapié. Han sido varios (por ej. Binswanger, 1981 y Assoun, 1984) los que han puesto de manifiesto el estatuto paradójico que la teoria de Freud demostraría en este punto.
} 
sublimación en el planteo freudiano. Reprimido, lo sexual-infantil insiste en su búsqueda de satisfacción y esa insistencia tiene costos individuales (los sintomas y el padecer de la neurosis). Sublimado lo sexual-infantil, esos costos individuales son menores y el aporte para lo colectivo es mayor. Lo que justifica estos procedimientos es la neutralización de esa amenaza que lo infantil es para el psicoanálisis. La neurosis es un costo individual menor frente al enorme aporte que supone, como modo de tramitación de lo sexualinfantil, para lo colectivo.

La persistencia de ciertos componentes sexuales infantiles en el trascurso del desarrollo depende además de la intensidad con que se adhieren o fijan en el psiquismo las impresiones experimentadas, lo que Freud llama "adhesividad" [Haftbarkeit] o "fijabilidad" [Fixierbarkeit]. Este factor, que debe suponerse en la etiología de la neurosis y la perversión, se apoya en la comprobación del mayor peso que tienen las huellas mnémicas en la vida animica en comparación a las impresiones recientes. Esto sugiere el privilegio que tiene, en Freud, el pasado sobre el presente desde el punto de vista de la determinación psíquica. El sistema psíquico postulado por Freud es un sistema de representaciones entre las que destacan las pasadas por su mayor influencia psíquica, y entre éstas las infantiles.

La subjetividad postulada por el psicoanálisis será un producto de la conjunción y determinación recíproca de todo este conjunto de factores (desenfrenos sexuales, oleadas represivas, sublimaciones, adhesividad). La específica constitución de un individuo, esto es, la intensidad relativa de sus componentes sexuales, se conjuga con los factores accidentales, es decir, las vivencias experimentadas en su desarrollo (y entre estas ocupan un lugar predominante, como vimos, las vivencias infantiles), y con el nivel de adhesividad, en una relación de cooperación recíproca, para determinar el devenir sexual y no sexual de un individuo ${ }^{2}$. Lo sexual-infantil, en su

\footnotetext{
2 No desconocemos la importancia que, desde la perspectiva de la temporalidad y la causalidad psíquica, tiene la noción de "posterioridad" [Nachträglichkeit] para Freud. Habría que incorporarla a este esquema si es que buscáramos dar cuenta de la orientación temporal que, en Freud, se vincula con cierta eficacia psíquica. Si la omitimos en nuestra argumentación es porque ésta pretende aislar, de la complejidad de la cuestión etiológica en Freud, no el movimiento (retroactivo) de la eficacia psíquica sino la estructura (esto es, el conjunto de elementos a los que nos referimos) que la explica, y en particular la situación de la infancia en la misma.
} 
específica mezcla de expresión, represión y sublimación, será, en este sentido, el factor de mayor determinación subjetiva.

\section{2. b. Lo sexual-infantil como lo originariamente reprimido}

Tanto fue el poderío causal otorgado por el psicoanálisis a la sexualidad infantil, tanta fue la peligrosidad que le asignó, que ésta no podía menos que ser remitida a las profundidades olvidadas del psiquismo. En efecto, para Freud, los primeros años de la infancia, en rigor, todo el periodo que abarca hasta la declinación del Complejo de Edipo y la entrada en el período de latencia sexual, quedan cubiertos por la denominada "amnesia infantil" [infantile Amnesie], la cual deja tras sí un acervo de huellas mnémicas sustraído de la conciencia por medio de un proceso que Freud designa con el término de "represión primaria y originaria" [Urverdrängung], y que diferencia de la "represión propiamente dicha o represión secundaria", aquella que sucede "con posterioridad" [Nachdrängen].

La postulación de un proceso tal responde, para Freud, a la necesidad teórica de postular una instancia inconsciente inicial que arrastraría hacia sí todo lo que la represión propiamente dicha repulsa, con posterioridad, de la conciencia. Para Freud, ninguna representación puede ser reprimida si no se experimenta, simultáneamente a la acción de repulsa ejercida por la represión propiamente dicha, una atracción proveniente de contenidos que ya son inconscientes. La amnesia infantil, y la represión de la que surge, serian, de este modo, las condiciones de posibilidad de todas las represiones ulteriores.

El propio Freud establece que los contenidos que deja tras sí la represión originaria son representaciones infantiles cuyo carácter sexual se deduce al considerar que la amnesia infantil no es producto de una inmadurez funcional sino precisamente de una represión, y que, en Freud, son las pulsiones sexuales las que sufren tal desenlace en función de la amenaza que representan para la vida cultural, y de su disfuncionalidad para la vida adulta y normal posterior. Esto sugiere que lo inconsciente originario estará constituido por representaciones de carácter sexual-infantil. Esta hipótesis se ve confirmada si observamos que, en su análisis del caso Schreber, Freud 
(1910/2010) describe como fijación este primer tiempo de la represión, esto es, en términos de una inhibición del desarrollo. Así, la represión originaria no detentaría en lo inconsciente sino aquellas pulsiones cuyo desarrollo libre hubiese resultado problemático en virtud del vínculo de oposición existente entre la sexualidad y la cultura.

En la lectura de ciertos autores, la teoría freudiana de la represión originaria supondría toda una serie de problemas. Se ha dicho, por ejemplo, que Freud no habria logrado delimitar con precisión la prioridad que el otro tendría en la constitución originaria del inconsciente. En Freud, la prioridad del otro se da por asumida pero en un marco en el que se presta a cierta equivocidad. Este descuido no sería de importancia de no conllevar, en la lectura de estos autores, consecuencias tan significativas como para poner en cuestión la operación de descentramiento que el planteamiento freudiano del inconsciente habilitó con una contundencia sólo equiparable, hasta ese entonces, a la evidenciada por las nociones nietzscheanas de "sí mismo" [Selbst], “cuerpo" [Leib] o "ello" [Es].

El representante más importante de este punto de vista fue Laplanche. En la tesis de Laplanche (1996), la prioridad del otro por sobre el sujeto sólo marca un momento inicial y efimero en la obra de Freud, pues se remonta a los primeros años de sus trabajos psicoanaliticos hasta 1897, período que coincide con su teoría seductiva. Éste fue, para Laplanche, el momento más profundamente copernicano de la obra de Freud, pues la teoría seductiva, si bien rápidamente olvidada, le permitió, en aquel entonces, articular un descentramiento radical del sujeto al situar el inconsciente del lado del otro, es decir, implantado al sujeto por un otro prioritario y originario. Esta perspectiva, en cuya delimitación la importancia de Lacan (del que Laplanche busca distanciarse) fue decisiva, es lo único que permitiría, para este último, situar y conservar al inconsciente en su extranjeria, ya que plantearlo en los términos de un acervo natural, central y fundamental de pulsiones reprimidas no haría sino conducir a un re-centramiento y a un cerramiento de la teoría sobre el sujeto pulsional y a un desconocimiento de la importancia determinante y originaria del otro. El "ipsocentrismo" (Ibíd.: 130) en el que recayó Freud desde 1897 al plantear al inconsciente pulsional y originario como centro y fundamento del sujeto no pudo más que cancelar 
el potencial conmocionante (en relación a todo centro, núcleo o arkhé) que la doctrina supo insinuar en un primer momento. Este fue, para Laplanche, el destino de la doctrina desde el momento en que abandonó la teoría seductiva.

En segundo lugar, la teoría freudiana de la represión originaria dificultaría la posibilidad de plantear nuevas y también originarias marcas, no necesariamente infantiles sino derivadas de todo encuentro con lo ajeno. En Freud, lo constituido en ese momento originario se organiza en el psiquismo oponiéndose a nuevos actos instituyentes, registrados como amenazas. En nuestro medio encontramos, en la figura de Berenstein, uno de los representantes más significativos de este punto de vista: fue precisamente aquí donde este autor situó su crítica a la primacía freudiana de lo infantil en la determinación psiquica. Para este autor, fue por carecer de una conceptualización acerca de lo que excede la representación que el psicoanálisis se vio condenado a esa primacía explicativa de lo infantil como origen y determinación fundamental del sujeto. Al edificarse bajo la égida de la representación, el psicoanálisis no pudo más que deducir una adhesividad de las primeras representaciones infantiles y una continuidad psíquica desde esas primeras huellas. "He ahí el origen -dirá Berenstein- y los encuentros con los otros serán conocidos desde alli y remitirán en su significado a una búsqueda de ese origen fantaseado" (2008: 98).

De aquí la importancia del concepto de "ajenidad" (definido como aquello del otro que no está recubierto por la representación o que excede el objeto proyectado, y que, en tanto tal, se impone sobre el sujeto, lo marca y lo obliga a hacer algo que terminará modificándolo), y de lo "actual" (es decir, de todas aquellas marcas instituidas en el "espacio público", esto es, en las relaciones de poder entre dos o más sujetos, que exceden lo pulsional y lo infantil, y tienen múltiples determinaciones cruzadas), en el planteo de Berenstein. El sujeto se instituiría no sólo a partir de lo sexual-infantil sino de todas aquellas relaciones actuales que exceden el registro representacional y hacen pensar en un sujeto indefinido y abierto, opuesto al homo clausus que ha definido, en la pluma de Norbert Elias (1994), al sujeto psicoanalitico, determinado fundamentalmente por esa sexualidad infantil 
cuya represión instituyó una marca -lo inconsciente originario- a la que remiten las manifestaciones del sujeto.

En Freud, los vínculos sexuales originarios permanecerán, en efecto, como la referencia que el individuo intentará restaurar en toda relación de amor. La teoría freudiana de los dos tiempos de la elección de objeto confirma esta perspectiva: en un primer momento las aspiraciones sexuales infantiles no trascienden los límites familiares (el deseo le pertenece a los padres); en un segundo momento, si bien dichas aspiraciones renunciarán a los objetos infantiles, éstos continuarán articulando las elecciones posteriores (el deseo ya nos les pertenece a los padres, pero éstos, habiendo sido negados, continúan indicándole la trayectoria).

Es decir que la elección de objeto, en su segundo tiempo, se realiza mediante un apuntalamiento en los modelos infantiles que nunca ceden su hegemonía. La inclinación infantil hacia los padres, si bien es la más importante, no es la única que, renovada en la pubertad, influye en la elección de objeto; otras inclinaciones pueden ser determinantes. Pero lo que comparten todas ellas es su referencia a la infancia. La infancia surge nuevamente como el factor más determinante del destino del individuo, quien no perseguiria en su vida sino modelos infantiles: "Innumerables particularidades de la vida amorosa de los seres humanos [...] sólo pueden comprenderse por referencia a la infancia y como efectos residuales de ella" (Freud, 1905/2008: 208).

\section{2. c. La familia en tanto agente de sexualización}

La sexualidad infantil se inicia, para Freud, en la experiencia de satisfacción, por apuntalamiento en una de las funciones, la nutricional, que sirven para la conservación de la vida, y a partir de un objeto exterior, el pecho materno. Sólo en un segundo momento, cuando el niño intenta repetir la experiencia de satisfacción, su quehacer sexual se divorcia de la necesidad nutricional, cobrando relevancia por sí mismo: el ejercicio sexual allí nacido no será sino el intento de renovar esa primera experiencia de placer. Pero en este segundo momento, la pulsión sexual no sólo se independiza de la nutricional sino también del mundo exterior, es decir, se vuelve autoerótica. 
Así, ya desde un origen, las relaciones del niño con su madre estarán saturadas de excitaciones y satisfacciones sexuales reciprocas. Para Freud, la madre toma a su hijo como sustituto de un objeto sexual, y de ese modo desempeña la importante función de despertar la pulsión sexual de su hijo: "Cuando enseña al niño a amar, [la madre] no hace sino cumplir su cometido; es que debe convertirse en un hombre integro, dotado de una enérgica necesidad sexual, y consumar en su vida todo aquello hacia lo cual la pulsión empuja a los seres humanos" (Ibíd.: 204). El otro, desde la experiencia de satisfacción y en virtud de la función referida, deviene un agente de sexualización.

Sin embargo, la función de este otro también puede ejercerse según una modalidad que puede alterar el curso normal del desarrollo del niño, llevándolo hacia la vida sexual perversa, y perjudicando "la posibilidad de educar[1o]" (Ib.: 214). Freud ejemplifica esto con el autoerotismo genital: la masturbación que se observa con el breve despertar de la sexualidad hacia el cuarto año de vida es promovida, dirá Freud, por ciertas contingencias externas, en particular, por la seducción ejercida por adultos o por otros niños que tratan prematuramente al niño como objeto sexual enseñándole la satisfacción de la zona genital en un momento del desarrollo en el que aún no se encuentra preparado para ello. A la luz de estas consideraciones, el otro aparece, en Freud, como un agente de sexualización susceptible de realizar su agencia de acuerdo a intensidades y tiempos que pueden o no ser favorables a la constitución sexual normal, o lo que es igual, genital, del niño; es decir, o bien como "agente de normalización sexual", o bien como "agente de seducción".

Se observa la doble función que tiene la familia en este planteo de Freud: primero debe despertar la sexualidad del niño, convertirlo en un "hombre integro", dotarlo de la suficiente energía para motorizar su rendimiento productivo, y hacerlo por medio de un juego adecuado de intensidades, de tiempos y espacios para atemperarla y hacer que transite el camino de la norma; y luego debe sofocar esa sexualidad en el momento en que ésta comienza a entrar en peligrosa contradicción con el orden cultural.

Aquí es donde Laplanche sitúa su crítica a la teoría pulsional y al descentramiento fallido a que condujo el psicoanálisis freudiano. Lo que las 
consideraciones previas demuestran, para Laplanche, es que el inconsciente (das Andere) sólo surge y se sostiene por la seducción ejercida por la otra persona (der Andere). La revolución copernicana supuesta por la teoría de Freud radica precisamente en situar el centro de gravitación no en el sujeto sino en el otro; pero si insistimos en borrar el primado de esta alteridad externa, la revolución resulta interrumpida o inacabada: "Que la alteridad de la otra persona se desdibuje, que se la reintegre bajo la forma de mi fantasía del otro, de mi "fantasía de seducción", y la alteridad del inconsciente correrá peligro" (Laplanche, 1996: 30).

La seducción laplancheana se aproxima a lo que aquí llamamos sexualización. La seducción, la del adulto sobre el niño es, en Laplanche, el momento prioritario y fundante en la constitución del sujeto. La revolución copernicana radical, acabada, supondría que partamos de la teoría de la seducción y de la admisión del primado del otro en la constitución psíquica, cosa que en Freud se vio mitigada por la prioridad que la teoría pulsional tuvo en su desarrollo, la cual terminó por encerrar al individuo dentro de sí mismo, determinado por sus inclinaciones innatas y relacionado con una realidad endógenamente construida a partir del interjuego entre esas pulsiones, perspectiva a la que Laplanche se refiere como "monadologia" o “idealismo biológico" (Ibíd.: 31).

\section{La infantile Sexualität freudiana: genealogia del concepto, operación del psicoanálisis y voluntad arqueológica}

Analizaremos ahora estos tres aspectos del problema freudiano de la sexualidad infantil desde algunos aportes de Foucault, Deleuze y Guattari, y Derrida. Estos autores son representantes destacados del campo de debate que, surgido en Francia desde la década de 1960, ha intentado poner en relación al psicoanálisis con el problema del poder y ha contribuido de ese modo a gestar una serie de discusiones que continúan hasta nuestros dias. Se ha destacado de la abundante bibliografia, aquellas obras de cada uno de estos autores en las que la polémica con el psicoanálisis resalta particularmente. 


\section{3. a. La sexualidad infantil y el nuevo espacio familiar}

Según establece Foucault, el poderío causal asignado por el psicoanálisis a la sexualidad infantil tiene su origen en un fenómeno que comienza a observarse en Europa durante el siglo XVIII, cuando se constata el surgimiento de toda una literatura que gira en torno del problema de la masturbación infantil. Se trata de un discurso que irá plagándose de toda una serie de exhortaciones, consejos e instrucciones dirigidos fundamentalmente a los padres y referidos a las modalidades a adoptarse para la evitación de la masturbación infantil, y a las instituciones y medicamentos que habrian de emplearse para curar a los masturbadores. Este discurso terminará por adoptar, en el siglo XIX, la forma de una campaña anti-masturbatoria, dirigida a las familias burguesas y aristocráticas ${ }^{3}$.

El control y la evitación de la masturbación infantil marcan, para Foucault, el inicio de un proceso de patologización de la sexualidad infantil que se profundizará y complejizará durante todo el siglo XIX y que estará anclado en y digitado desde el discurso y la práctica médica-psiquiátrica. Como consecuencia de este proceso, la sexualidad infantil terminará por ejercer, en el transcurso del siglo XIX y el XX, un "poderío causal inagotable" (Foucault, 2010: 226) que habrá que situar en la base de todas las enfermedades posibles y hasta de la muerte.

De acuerdo a la literatura de la época, la masturbación no surgiría naturalmente en el niño sino que sería despertada por una serie de accidentes externos, en particular, por la seducción ejercida por ciertos adultos del entorno inmediato del niño. Se trataría de todos esos personajes de la "intermediación familiar" que, como el criado, la gobernanta, el preceptor, el tío, los primos, etc., se ubican entre "la virtud de los padres y la inocencia natural de los niños, y [que van] a introducir la dimensión de la perversidad" (Ibíd.: 229). Es el deseo de estos adultos por los niños lo que constituye, según el saber de la época, el origen de la masturbación.

\footnotetext{
3 Para la familia del proletariado, Foucault sitúa otra campaña y otra problematización de la sexualidad. En todo el análisis foucaultiano que presentaremos a continuación no se trata sino de la familia burguesa y de la familia de la aristocracia.
} 
Lo que se requiere a partir de esta constatación es un estrechamiento de las distancias familiares que asegure la vigilancia total y continua por parte de los padres del cuerpo del niño, para suprimir todos aquellos accidentes externos que llevan al despertar de la masturbación: "Proximidad infinita, contacto, casi mezcla; asimilación imperativa del cuerpo de unos al cuerpo de los otros; obligación acuciante de la mirada, la presencia, la contigüidad, el contacto [...] Envoltura del cuerpo del niño por el cuerpo de los padres" (Ibíd.: 234): este será el objetivo de la campaña antimasturbatoria, la constitución de un nuevo cuerpo familiar.

Presenciamos así, hacia finales del siglo XVIII, una transición desde la familia burguesa de mediados del siglo XVIII, que era un amplio conjunto de relaciones de ascendencia, descendencia, colateralidad, primazgo, mayorazgo, alianza, etc., hasta la "familia-célula" que prevalecerá hasta nuestros días, caracterizada por ser un núcleo restringido, duro, sustancial, corporal, afectivo y sexual. Presenciamos, en otras palabras, un "proceso de acercamiento-coagulación, que permite definir, en la red amplia de la familia [relacional], una pequeña célula intensa que se reagrupa alrededor del cuerpo del niño peligrosamente sexualizado" (Ibíd.: 252).

Para Foucault, fue la racionalidad médico-psiquiátrica la que digitó la constitución del nuevo espacio familiar, y la que promovió el nuevo discurso sobre la sexualidad. De modo que el poder parental interno se conectó con un poder médico externo que hacía del espacio familiar un espacio de vigilancia y control permanente, y que intervenía, frente a cualquier fenómeno potencialmente patógeno, para hacerse receptora de la confesión sexual y correctora de la desviación. Así se explica el surgimiento de un "engranaje médico-familiar" que organiza un campo a la vez ético y patológico donde las conductas sexuales aparecen como objeto de vigilancia, control, juicio e intervención. Este engranaje no sólo procuró evitar o intervenir sobre la masturbación por sus efectos patógenos, sino que también asumió la importante función de designar qué era lo normal y lo anormal en el orden de lo sexual. Así, desde el siglo XIX, el engranaje médico-familiar pasó a funcionar como principio de normalización de la sexualidad. 
El interés médico por el cuerpo y sexualidad del niño buscaba la supervivencia del niño y su desarrollo "normalizado", es decir, subordinado a la utilidad del Estado. Todas estas intervenciones buscaban el ajuste progresivo de los individuos a las formas y relaciones de producción existentes. Esto era lo que subyacía, para Foucault, a la problematización decimonónica de la sexualidad infantil.

En el contexto de esta nueva configuración del espacio familiar, surgió, hacia finales del siglo XIX, la problemática del incesto. Las teorías médicas comenzaron a comunicar que el deseo de los niños va dirigido, desde un origen, a sus padres, lo cual condujo, para Foucault, a dos consecuencias fundamentales: por un lado, a una reapropiación de la sexualidad del niño por parte de los padres, en la medida en que se les comunica que el cuerpo sexual de sus hijos no sólo les pertenece por todas las razones aludidas sino también porque ese deseo se dirige a ellos; por otro lado, una trasgresión tan extrema situado en el corazón mismo de las relaciones padres-hijos justificó aún más la intervención legisladora y correctora del poder médico. Para Foucault, el mecanismo institucional y la "técnica de normalización" que surgió a finales del siglo XIX para ocuparse del incesto familiar y de todos los efectos perturbadores de la sexualidad infantil, fue el psicoanálisis.

\section{3. b. El psicoanálisis como función de disciplinamiento y como heredero del poder psiquiátrico}

Foucault (2008) sitúa el surgimiento del psicoanálisis en el marco de la denominada "función psi", esto es, del conjunto de dispositivos disciplinarios aparecidos a principios del siglo XIX para mitigar el debilitamiento de la soberanía familiar. La disciplina promovida por estos dispositivos fue la que comenzó a introducirse en el espacio familiar para ejercer esa vigilancia permanente a la que hicimos referencia, y la ocasional denuncia de las potenciales amenazas. Toda vez que la denuncia familiar tenía lugar, los dispositivos psi -psiquiátricos, psicosociológicos, psicopatológicos, psicoanaliticos, etc.- intervenian para re-familiarizar a todos aquellos individuos que se desajustaban de la soberanía familiar, lo cual era realizado 
según una tecnología y un discurso que tenía a esta soberanía familiar como referencia constante.

La disciplina es un poder esencialmente normalizador que busca la vigilancia y gestión del tiempo, la vida y los cuerpos de los individuos, para optimizar de ese modo sus comportamientos productivos y asegurar la reproducción de unas determinadas condiciones de producción. La función psi interviene toda vez que alguien no puede seguir la disciplina de la escuela, del taller o de cualquier otro ámbito de disciplinamiento. Acompañando la creciente disciplinarización de la sociedad, la función psi fue expandiendo su presencia y dominio para constituirse, a principios del siglo XX, en el discurso y la instancia de control permanente de todos los dispositivos disciplinarios, remitiendo a la soberanía familiar como "instancia de verdad a partir de la cual será posible describir y definir todos los procesos, positivos y negativos, que ocurren en los dispositivos disciplinarios" (Ibíd.: 111). Y el psicoanálisis será, en este contexto, para Foucault, "el más «discurso de la familia» de todos los discursos psicológicos [...] el discurso de verdad a partir del cual es posible analizar todas las instituciones disciplinarias" (Ibíd.: 112).

El psicoanálisis asumirá, en este sentido, el papel hegemónico que la psiquiatría moderna tuvo durante el siglo XIX, al tiempo que adoptará muchos de sus elementos constituyentes. La adopción de la problematización de la sexualidad infantil, de la voluntad de disciplinamiento del medio familiar, de un discurso y una tecnología centradas en la familia, de la problemática del incesto; etc.: en suma, la adopción, por los psicoanalistas, de toda una serie de elementos del saber y la práctica psiquiátricos decimonónicos, hace que se conviertan, como dice Foucault (2010), en los nuevos agentes de la normalización médica de la familia, o como dicen Deleuze y Guattari (2009), en los agentes de la antiproducción del deseo.

3. c. La operación psicoanalitica: Edipo, representación y trascendencia - el problema del origen 
¿En qué consiste la operación psicoanalítica? ¿Cómo lleva el psicoanálisis adelante la función que le fue asignada por los mecanismos de poder y de control social, a saber, la de gestionar el incesto familiar y la sexualidad infantil? El deseo -lo que Freud llamaba la "perversidad polimorfa" del infante, sus pulsiones desarticuladas, anárquicas- es por esencia, dirán Deleuze y Guattari, revolucionario: "toda posición de deseo, por pequeña que sea, tiene motivos para poner en cuestión el orden establecido de una sociedad [...] ninguna sociedad puede soportar una posición de deseo verdadero sin que sus estructuras de explotación, avasallamiento y jerarquía no se vean comprometidas" (Ibíd.: 121). La operación psicoanalítica frente a la amenaza del deseo será la de introducirlo dentro del triángulo familiar para de ese modo neutralizarlo, volverlo inofensivo.

Aquí es preciso distanciar la posición de estos autores de la de Foucault. La disciplina, para este último, tiende a la extensión permanente de los dominios y las formas de control para lograr el aumento organizado de las fuerzas. El poder disciplinario se ejerce positivamente sobre la vida, no busca ni la represión ni la neutralización de las fuerzas, sino su producción y multiplicación, mediante un control y una vigilancia permanentes y un código ético de normalización.

De alli la gran proliferación discursiva sobre el sexo de la que han sido testigos las sociedades disciplinarias. El psicoanálisis es ubicado en el contexto de esta productividad discursiva. Ahora bien, en esta proliferación existe el riesgo de la des-limitación, el peligro del desenfreno irreparable de la vida. Esta situación reclama la intervención de la negatividad del poderley, del poder-soberanía: el dispositivo disciplinario de sexualidad, decía Foucault (2013), tiende a sostener el viejo dispositivo soberano de la alianza.

En este punto preciso se alojó, como dijimos, el psicoanálisis, en el solapamiento entre dos regímenes de poder, uno basado en una ley prohibitiva, el otro basado en una vigilancia productiva. Así, el psicoanálisis constituiría, según Foucault, el esfuerzo teórico por reinscribir la sexualidad en el sistema de la ley, del orden simbólico y de la soberanía: "Es el honor político del psicoanálisis [...] haber sospechado [...] lo que podía haber de irreparablemente proliferante en esos mecanismos de poder que pretendian controlar y administrar lo cotidiano de la sexualidad: de ahí el esfuerzo 
freudiano [...] para hacer de la ley el principio de la sexualidad -la ley de la alianza, de la consanguinidad prohibida, del Padre-Soberano-, en suma, para convocar en torno al deseo todo el antiguo orden del poder" (2013: 142). En el corazón mismo de la sexualidad se sitúa, como principio de su constitución y clave de su inteligibilidad, la ley de la alianza, la relación padre-hijo, el incesto, lo cual permitió limitar el dispositivo de sexualidad sujetándolo sobre el sistema de la alianza. Si la sexualidad parecía extraña a la ley, los discursos surgidos desde el siglo XVII se encargaron de brindar tranquilidad al sostener que la primera no se constituía sino gracias a ésta: uno accede al deseo gracias a la madre-objeto y al signo soberano del Padre.

La familia no es entendida, en el planteo de Foucault, como una estructura social que excluye o refrena la sexualidad. El problema de la familia es ubicado, por Foucault, en el encabalgamiento entre estos dos regimenes de poder: asegura la producción de la sexualidad conservando los viejos sistemas de alianza; transporta la ley y la dimensión de lo jurídico hasta el dispositivo de sexualidad; y transporta la economía del placer y la intensidad de las sensaciones hasta el régimen de la alianza. Esta reunión de poderes es lo que explica la constitución de la familia corporal, afectiva, sexual, incestuosa, de la que hablábamos más arriba.

Para Deleuze y Guattari, lo que descubrió Freud fue ese campo productivo de líneas de fuga o desterritorialización que se escapan incesantemente resistiéndose a todo tipo de estructuración y organización, líneas que ponen en juego no sólo relaciones con el padre y con la madre sino también con el animal, el vegetal, con la política, con lo social, líneas que promueven todo tipo de devenires; ese campo de los objetos y las pulsiones parciales, de flujos intensivos cuya expresión se realiza en la infancia con toda naturalidad y que luego, por el disciplinamiento ejercido, se domestica y normaliza. Este inconsciente que constituye el descubrimiento freudiano fundamental es, para los autores, un “inconsciente rizomático" (Deleuze \& Guattari, 2006) en virtud de su carácter múltiple, inmanente, carente de formas, de génesis, de estructura y principio organizativo. Sólo hay allí relaciones de movimiento y reposo, velocidades y lentitudes, haecceidades, afectos e intensidades. No hay principio de 
subjetivación, sino más bien de desubjetivación. Es un "inconsciente huérfano" (Deleuze \& Guattari, 2009: 88), anedípico.

¿Qué es lo que hace el psicoanálisis con esta multiplicidad productiva e inmanente? Para Deleuze y Guattari, el psicoanálisis somete el régimen de la producción y la inmanencia al de la representación y la trascendencia, es decir: por un lado, la producción deseante queda aplastada y sometida a las exigencias de la representación: "ahí radica lo esencial: la reproducción del deseo da lugar a una simple representación, en el proceso de la cura tanto como en la teoría. El inconsciente productivo sólo da lugar a un inconsciente que sólo sabe expresarse -expresarse en el mito, en la tragedia, en el sueño [...] Como si Freud hubiese hecho marcha atrás ante este mundo de producción salvaje y de deseo explosivo, y a cualquier precio quisiese poner un poco de orden, un orden ya clásico, del viejo teatro griego" (Ibíd.: 60). Así, el inconsciente pasa de ser una fábrica, un taller, a ser un teatro, una puesta en escena. Por otro lado, el psicoanálisis convierte la inmanencia en trascendencia, y así introduce el problema del sentido: el inconsciente se convierte en un plan oculto que no puede aprehenderse por sí mismo sino que sólo puede inferirse a partir de lo dado: todas las manifestaciones del paciente (su deseo, su angustia, sus fantasias) remiten a las preguntas: ¿Qué desea realmente detrás de ese deseo que manifiesta? ¿Qué significa su angustia? ¿Qué se esconde detrás de sus fantasias? Se trata aquí, para Deleuze y Guattari, de un plan de trascendencia a la vez genético y estructural: cada enunciado o deseo del paciente se ajusta a un eje genético o a una estructura sobrecodificada (Edipo: génesis de la neurosis, estructura que organiza las relaciones de parentesco) que ordena el inconsciente, sacando calcos del mismo que aíslen o seleccionen lo que luego se buscará reproducir hasta el infinito: se angustia porque desea a la madre y teme al padre. El calco organiza el rizoma: inyecta redundancias, neutraliza las multiplicidades, y lo que queda es un inconsciente representativo, cristalizado en complejos codificados. Este inconsciente oculto, trascendente, es la condición de posibilidad de la hermenéutica psicoanalítica.

Por el contrario, en el plan de inmanencia, el inconsciente deviene maquínico, no representativo; no es estructural ni genético y no plantea 
problemas de sentido, sino de uso: "La cuestión del deseo no es "¿qué es lo que ello quiere decir?", sino cómo marcha eso. ¿Cómo funcionan las máquinas deseantes?” (Ibídem., 2009: 114). La interpretación se vuelve ineficaz y da paso a la experimentación, ya que al inconsciente no hay que encontrarlo sino que hay que construirlo: lo importante es producir inconsciente, nuevos enunciados, otros deseos. En suma, se trataría de la productividad de un deseo intensivo e ilimitado, cuya libido carga un campo que hace estallar el marco edipico-familiar e invade todo el mundo social, histórico, político, cultural, racial, etc. Los padres no son los organizadores simbólicos del inconsciente, las figuras primordiales a partir de las cuales todo otro agente de la colectividad constituye un derivado o substituto; son inductores cualesquiera, encargados de desencadenar procesos que igualmente puede ser desencadenados por cualquier otra figura del campo histórico, político, social, cultural, etc.

Las exigencias de la representación y la trascendencia configuran un contexto donde el progreso de la cura quedaría subordinado a la medida en que la palabra pueda acercarse al sentido de los sintomas y expresar el deseo que éstos ocultan. Sucede que este progreso en la cura se encuentra con un límite (lo que Freud llama "ombligo del sueño" (1900/1986: 519), que es el lugar del origen del deseo y un punto de absoluta inanalizabilidad. Que el psicoanálisis persigue ese punto a pesar de su imposibilidad, es algo sobre lo que Derrida (2006) ha hecho referencia en un abordaje que problematiza la noción de origen en psicoanálisis.

Para Derrida (2006), Freud permaneció fiel al concepto tradicional del análisis, aquel que atraviesa las dialécticas platónica y hegeliana, las analiticas de Aristóteles y de Kant, y, en suma, toda aquella historia de la filosofía que pertenece al orden de la representación o de la conciencia ideal y que, en tanto tal, nunca podria intervenir de manera efectiva para levantar ningún síntoma o resistencia cuyas claves estén jugadas en un campo de fuerzas que exceda las encrucijadas del sentido. El concepto tradicional del análisis al que hace referencia Derrida se erige en torno a dos motivos fundamentales: un motivo arqueológico o anagógico, orientado a la búsqueda de lo principal y originario, de lo más simple y elemental, de ese último elemento indescomponible; y un motivo lítico, litológico o filolítico, 
orientado a la descomposición, desligazón, liberación, solución y disolución, y al mismo tiempo, al acabamiento final, pues de lo que se trata aquí es, en rigor, de un movimiento escatológico, "como si el análisis portara la muerte extrema y la última palabra, así como el motivo arqueológico que apunta a lo originario se volvería hacia el nacimiento” (Ibíd.: 37).

El planteo de Derrida sugiere que desde el "ombligo del sueño", desde ese lugar que resiste inanalizable al análisis, el deseo apela al análisis que prohíbe, y lo hace hablar, "respondiendo sin responder, sin decir sí ni no, sin aceptar ni oponerse, hablando pero sin decir nada" (Ibíd.: 43). De aquí dos necesidades: la de plantear un double bind que provoca al infinito toda analítica y toda dialéctica pero sólo para resistírseles, y la de pensar esta resistencia como lo que Derrida denomina "restancia del resto" (Ibíd.: 45), es decir, no de manera simplemente ontológica, porque la restancia del resto no es o no se presenta ${ }^{4}$. El double bind conduce a un "drama interminable del análisis" (Ibíd.: 49), esto es, a un principio de análisis interminable radicado en la perpetua posibilidad de la disociabilidad. Esto delata la invencibilidad del principio filolítico del análisis, y su diferencia con el arqueológico que siempre está destinado a fracasar. En 1897 Freud confesaba a Fliess: "Ya no creo más en mi "neurótica", es que las continuas "desilusiones en los intentos de llevar mi análisis a su consumación efectiva", lo habían hecho renunciar a la pretensión de avanzar, en la cura, hacia el "completo domeñamiento de la inconsciente por lo conciente" (1950/2010: 301-2). El double bind opera como un resto que resiste, en su ligazón irreductible, como lo último desconocido para el análisis interminable que él pone no obstante en movimiento.

El double bind opera como operan todas las "figuras de lo indecidible", portando predicados contradictorios o incompatibles en su entrelazamiento, anunciándose en el análisis como huellas que no son un todo y que no son idénticas $\mathrm{u}$ homogéneas a sí mismas, sino que restan inanalizables. El double bind constituye la condición de la constitución de las identidades, de

\footnotetext{
${ }^{4}$ La restancia tiene que ver, para Derrida, con ese modo de la ontología que es la hantologie, una "ontología asediada por fantasmas". "El fantasma es lo que da que pensar", dirá Derrida. El fantasma no está situado en un lugar preciso; transita entre umbrales, entre la vida y la muerte. No habita sino que asedia (hanter). Se torna algo casi innombrable que resiste todo saber, toda ontologización, toda dialectización, y todo dominio (Cfr. Cragnolini, 2002).
} 
la idealidad, y en general de todo concepto, y es por ello, el devenir-objetivo del objeto y el devenir-subjetivo del sujeto, y en consecuencia, el deveniranalizable en general; pero también constituye lo que perturba todo análisis, al resistirse a las oposiciones binarias y jerarquizadas que justifican todo principio de distinción.

Se debe, dirá Derrida, analizar el "se debe" del deseo psicoanalítico que busca la descomposición progresiva para alcanzar una simplicidad elemental. Pero analizar ese deseo no significa renunciar a su ley y suspender el orden de la razón, del sentido, y del interrogante de origen que los atraviesa; también es necesario dar cuenta de la demanda arqueológica del psicoanálisis. He aquí entonces, dirá Derrida, el double bind, la paradoja de un doble "se debe", la cuestión del análisis mismo. No se trata, dirá Derrida, de analizar integralmente el double bind, porque un double bind jamás se analiza integralmente; tampoco se trata de asumirlo, porque el double bind nunca se asume sino que sólo se sufre o soporta en la pasión. Para ello, primero hay que abandonar la creencia de que sólo se trata una patología clasificable y circunscribible; y luego considerar que "sin ese double bind y sin la prueba de aporía que él determina, sólo habría programas y causalidades, nunca habría tenido lugar ninguna decisión. Ninguna responsabilidad. Yo llegaría incluso a decir que no habría tenido lugar ningún acontecimiento. Ni siquiera el análisis. Ni siquiera el lugar” (Derrida, 2006: 59).

Para Deleuze y Guattari, la operación psicoanalitica sólo puede comprenderse en el marco de las instancias superiores de poder, de lo que los autores llaman, para oponerla a la represión familiar-psicoanalítica, represión general. La represión que plantea el psicoanálisis es un medio al servicio de esta represión general que busca la conservación y reproducción de una forma determinada de producción social, mediante la domesticación de la producción deseante.

Esta represión general se ejerce, para Deleuze y Guattari, de acuerdo a una doble operación: por un lado, delega su poder a una instancia represora menor que la acerca a los cuerpos y a los comportamientos de los individuos, y por el otro, recubre la producción deseante con una imagen desplazada de ella. El agente delegado de la represión general es la familia 
afectiva y estrecha de la que decía Foucault que era la encargada de prolongar hacia el niño ciertas relaciones de poder. La imagen desplazada de la producción deseante son las pulsiones incestuosas: en efecto, las instancias superiores no se interesan por las pulsiones incestuosas familiares sino por el potencial disruptivo, desestabilizador del deseo ("el deseo no amenaza a una sociedad porque sea deseo de acostarse con la madre, sino porque es revolucionario" (Ibíd.: 122)). El Complejo de Edipo, y la problematización de la sexualidad infantil, es fruto de esta doble operación; es la "justificación cultural” que la represión general necesita, la representación que promueve para asegurar su intervención efectiva, para formar sujetos dóciles y asegurar, mediante la conjuración del "poder de rebelión y revolución del deseo", la reproducción de las formas de producción dadas: "Es la represión general del deseo [...] la que actualiza a Edipo e introduce al deseo en este atolladero querido, organizado por la sociedad represiva" (Ibid.: 124).

El sujeto que resulta de la operación que describen Deleuze y Guattari es un sujeto apto para adaptarse al circuito de la producción social. Se trata de una subjetividad edipizada, intervenida por todas las maniobras de poder que buscan atenuar la amenaza de ese deseo cuya expresión en la infancia es normal pero que luego debe ser sofocado por atentar contra el sostenimiento de ciertas condiciones de producción. Desde esta perspectiva, los psicoanalistas son agentes de un poder que los excede y el Complejo de Edipo es la herramienta que emplean como medio de normalización. En esa función normativa del Complejo de Edipo el propio Lacan (1996; 2009) nunca dejó de insistir.

\section{3. d. Instinto sexual, placer, estado, infancia: instrumentos teóricos para una generalización de la psiquiatria}

Como consecuencia de su expansión a ámbitos que no formaban anteriormente parte de su órbita de poder, la psiquiatría moderna presenciará, durante todo el siglo XIX, un aumento considerable de su capacidad y espacio de influencia hasta terminar por convertirse en una tecnología del individuo indispensable para el funcionamiento de los principales mecanismos de poder, presente en espacios tan diversos como la 
familia, la escuela, el tribunal, el taller, la prisión, etc. Para ejercer su influencia en un campo tan vasto y heterogéneo, la psiquiatría se verá en la necesidad de construir todo un aparato discursivo, analitico y conceptual, que permita explicar todo, desde el autoerotismo infantil hasta el asesinato: para Foucault, ésta será la tarea que se asignará la psiquiatría a partir de 1840-1850.

Surgirán de este modo una serie de nociones fundamentales que funcionarán como instrumentos para la generalización de la psiquiatría. Una de estas nociones es la noción de instinto, que desde el engranaje psiquiátrico-familiar, pasará a especificarse, dada la problematización de la sexualidad que conllevó el enganche de la psiquiatría con la familia, en instinto sexual. La función general que adoptó la psiquiatría en el siglo XIX quedaba de este modo subordinada, en parte, a su capacidad de organizar un campo unitario del instinto y de la sexualidad, es decir, a su capacidad de mostrar la influencia del instinto sexual en la formación no sólo de todas las enfermedades mentales, sino también, y aquí reside la novedad, de todas las anomalías del comportamiento.

Como primera realización de esta empresa deben situarse los grandes tratados de psicopatología sexual del siglo XIX, el primero de los cuales es la Psychopathia sexualis de Heinrich Kaan, publicado en Leipzig en 1844. Del análisis de Kaan surge, por vez primera, esta idea -tan presente, como vimos, en el planteo freudiano- de que el instinto es naturalmente anormal, y que este lazo "intrínseco y confuso" entre naturalidad y anomalía del instinto, aparece de manera "privilegiada y determinante" en la infancia. E1 instinto sexual será, para Kaan, el punto de origen no sólo de los trastornos físicos sino también, lo que no se encontraba en la campaña antimasturbatoria, de toda una serie de trastornos que son a la vez sexuales y psiquiátricos. Así, con el libro de Kaan se da inicio a una psiquiatría organizada en torno a la noción de instinto sexual y a una formalización rigurosa de la sexualidad y de las aberraciones sexuales en el campo de la psiquiatría. La campaña antimasturbatoria fue el eslabón inicial de un proceso que aquí desembocaría. Las enfermedades mentales y fundamentalmente todos los comportamientos normales y anormales serán 
explicados a partir del mecanismo del instinto sexual, el cual comienza adoptar un papel destacado en relación a todos los demás instintos.

La psiquiatría promueve al mismo tiempo la noción de placer y postula una inadecuación fundamental entre placer y reproducción, es decir, postula que el placer puede ser logrado por el instinto sexual a través de modos que no se corresponden, o que incluso atentan contra los actos reproductivos que aseguran la supervivencia de la especie. La introducción del problema del placer en la psiquiatría permite, de este modo, explicar, por la desconexión natural del instinto sexual respecto de la reproducción, el conjunto de las aberraciones sexuales y de los comportamientos anormales, es decir, todas aquellas manifestaciones susceptibles de psiquiatrización. Para Foucault, las nociones de instinto sexual y de placer serán los instrumentos teóricos fundamentales que permitirán a la psiquiatría elaborar el edificio conceptual requerido para recorrer todo el ámbito que le asigna la organización de los mecanismos de poder.

A diferencia de la época de los alienistas, centrada en las figuras de Esquirol y Pinel, lo que está en juego para esta psiquiatría no son las discontinuidades introducidas por una exageración o proliferación del instinto: no hay enfermedad del instinto, dirá Foucault, éste continúa siendo lo que es, y precisamente esto que el instinto naturalmente es resulta problemático si no intervienen aquellas instancias superiores encargadas de inhibirlo o controlarlo. Para la nueva psiquiatría lo que está en juego, en consecuencia, es el estado permanente que subyace a y sostiene los fenómenos anormales en la medida en que no ejerce la referida inhibición o control de un instinto sexual que logra, de este modo, expresarse normalmente, es decir, según su propio régimen, pero anormalmente en el sentido de su no funcionalidad respecto del orden productivo. La presencia de este estado es lo que legitima la psiquiatrización de los comportamientos.

La noción de estado fue introducida por J-P Falret en los años 18601870. Fue ésta la noción fundamental que contribuyó a articular la relación entre el poder médico y el conjunto de las anomalias que pasó a ser el objeto fundamental de la psiquiatría a partir de entonces. El estado no es una enfermedad, es una especie de "fondo causal permanente", de "basamento anormal", sólo a partir del cual pueden desarrollarse secundariamente toda 
una serie de enfermedades. Constituye, como dice Foucault (2010), una especie de "perturbación general en el juego de las excitaciones y las inhibiciones" (290) que hace que aquello que deberia inhibirse o controlarse se libere o se exprese según su régimen, normal en sí mismo, pero anormal para el funcionamiento productivo de la sociedad. La noción de estado también posee una ventaja que es su formidable capacidad de integración, en virtud de que puede admitir en su campo cualquier conducta a partir del momento en que es fisiológica, psicológica, sociológica, moral y hasta jurídicamente desviada.

El desarrollo normal quedaría, de este modo, asegurado sólo por el dominio y sometimiento, ejercido en un segundo momento por las instancias superiores, del instinto sexual para que no quede librado a su curso natural y espontáneo. Lo que produce el estado es precisamente una interrupción del desarrollo, o bien una regresión del mismo a un estado anterior, que hace que el comportamiento quede sometido al régimen de lo infantil, que es donde el instinto se expresa natural y espontáneamente. Presenciamos así desde principios del siglo XIX, una psiquiatrización basada en la infantilización del comportamiento, de la moralidad y de la sexualidad del individuo; en la irrupción, por el control deficiente ejercido por las instancias inhibitorias superiores, de lo infantil en la vida adulta.

Éste es, para Foucault, el punto fundamental: la nueva posición del niño y de la infancia respecto a la práctica psiquiátrica. Hay "una puesta en continuidad, o mejor, una inmovilización de la vida, de la conducta, de las actuaciones alrededor de la infancia; [...] esto es lo que va a permitir fundamentalmente la psiquiatrización” (Ibíd.: 279). Con la nueva psiquiatría, la infancia se convierte en el gran instrumento de psiquiatrización. De aquí en más, la psiquiatría sólo logrará captar al adulto a través de la infancia. Desde principios del siglo XIX, la infancia pasa a operar, para Foucault, como principio de generalización de la psiquiatría. De aquí en más, todo comportamiento infantil (en la medida en que puede fijar el desarrollo) y adulto (en la medida en que se asimile a las conductas del niño) quedará sometido a la órbita de vigilancia y al poder de la psiquiatría.

Si la psiquiatría logra generalizarse a costa de la infancia es porque ésta le ofrece como objeto ya no una enfermedad o un proceso patológico sino, 
como dijimos, un cierto estado que, al interrumpir el desarrollo, promueve un funcionamiento que, sin ser patológico, no es sin embargo normal. Así, el dominio de objetos de la psiquiatría estará constituido, de aquí en más, por un estado que habría que caracterizar de anormal en virtud del ejercicio deficiente que demuestra a la hora de limitar el alcance de lo sexual-infantil. Lo normal, para la nueva psiquiatria, es que el instinto sexual que busca naturalmente una expresión múltiple y polimorfa, sólo se exprese de manera originaria, esto es, en la infancia. Lo anormal sería la expresión del instinto sexual según su régimen natural e infantil en la vida adulta, o más precisamente, en un momento del desarrollo donde su carácter múltiple y polimorfo debería estar ya limitado y regulado. En este contexto, donde lo que prima es el régimen de lo normal-anormal, la patología sería sólo un fenómeno secundario, un corolario del estado que es lo fundamental.

De modo que, al concentrarse cada vez más en la infancia, la psiquiatría pudo llegar a constituirse en la instancia general para el análisis y el control de los comportamientos: desde mediados del siglo XIX, fue ella la que comenzó a dictaminar qué era lo normal y lo anormal en el campo de las manifestaciones comportamentales. A diferencia de la psiquiatría de los alienistas, la psiquiatría moderna deja de ser una técnica y un saber de la enfermedad (o sólo lo es secundariamente) para pasar a ser una psiquiatría de las desviaciones o anomalías del comportamiento, y una psiquiatría que hace del desarrollo normal su referencia fundamental. Es así como el ámbito de influencia de la psiquiatría queda expandido: si antes lo que legitimaba la intervención psiquiátrica era la enfermedad, ahora lo es toda una serie de “objetos despatologizados", en rigor, toda una amplia serie de objetos cuya característica fundamental es su desviación respecto del desarrollo normal.

Las grandes estructuras teóricas erigidas desde finales del siglo XIX (y entre ellas habrá que situar al psicoanálisis) no son, para Foucault, sino la expresión de esta tentativa de poner en relación un poder médico con un ámbito de “objetos despatologizados". Surgen así las grandes descripciones nosográficas cuya tarea es la de organizar y describir toda una serie de conductas desviadas, aberrantes, excéntricas, que aparecen a partir de entonces como sintomas bien especificados: la "inversión" y la "agorafobia" descriptas por Westphal en 1870 y 1872 respectivamente, el 
“exhibicionismo" descripto por Lasègue en 1877, y la "cleptomanía” descripta por Gorry en 1879, son algunos ejemplos. Los Tres ensayos de Freud pueden ser comprendidos en este contexto, y en una relación de continuidad respecto de estos trabajos precedentes. El régimen de lo normal-anormal que prevalece en esta obra de Freud sólo se comprende a luz del nuevo objeto que se impuso la psiquiatría desde el siglo XIX: ya no la enfermedad sino lo anormal dado por la invasión de lo sexual-infantil en la vida adulta.

Foucault, Deleuze y Guattari parecen acordar en situar al psicoanálisis no sólo en una relación de continuidad respecto de la psiquiatría decimonónica sino también en una posición hegemónica respecto de todos aquellos otros dispositivos que, como vimos, surgieron para el disciplinamiento de los individuos y su ajuste al orden productivo social. E1 psicoanálisis hereda de la psiquiatría moderna no sólo la problematización de la sexualidad infantil sino también aquellas nociones que la psiquiatría fue construyendo para legitimar su expansión a todo el campo del comportamiento: la noción de instinto sexual, de estado, de placer, las descripciones nosográficas de las aberraciones, se instalan, en efecto, en el corazón de la teoría y la técnica psicoanaliticas. Lo que subyace a este saber y a esta técnica son ciertas operaciones de poder que delegan en una familia de ahora en más gestionada de manera fundamental por el saber psicoanalítico, el disciplinamiento del "potencial disruptivo del deseo". E1 psicoanálisis pasa, a partir del siglo XX, a ocupar el punto central de este campo de saber y de poder organizado y gestionado, durante todo el siglo XIX, por la psiquiatría.

\section{Conclusión}

Hemos ubicado al psicoanálisis en el contexto de aquella proliferación discursiva que desde el siglo XVII surgió en torno al sexo para lograr ciertos efectos en su economía misma. Al evidenciar esta producción discursiva, Foucault logró poner en cuestión la noción de una naturaleza esencialmente negativa del poder y la idea de que el sexo habría sufrido en los últimos siglos una represión por causa de su presunta incompatibilidad con el orden productivo. Se trató, para Foucault, menos de una represión del sexo que de 
la producción de la sexualidad como dispositivo histórico de saber y de poder.

Esta constatación permite conmover el esquema que ha homologado lo social con lo represivo y el sexo con la libertad, esquema que está parcialmente supuesto en la perspectiva de Deleuze y Guattari: el sexo, decian los autores, es revolucionario y la sociedad ejerce sobre él una represión generalizada (para cuya efectividad trabajaría el psicoanálisis) que tiende a la conservación y reproducción de determinada forma de producción.

Para Foucault, el sexo no es algo que se buscó reprimir o neutralizar sino algo que se produjo como punto ideal, especulativo, como ficción necesaria para asegurar el funcionamiento de aquel dispositivo de sexualidad surgido en el marco de un poder no conservativo y reproductivo, sino proliferante y productivo. Este poder, que Foucault llamó disciplinario, buscó la expansión e intensificación vigiladas, controladas y administradas de la vida, no mediante los dictámenes de la ley prohibitiva sino mediante los requerimientos disciplinarios de la normalización. Se buscó, de este modo, desde el siglo XVII, no tanto la represión o neutralización de fuerzas improductivas o indóciles, sino la proliferación ordenadas de las fuerzas colectivas e individuales.

Foucault entiende que todas las sexualidades periféricas y múltiples surgidas con particular énfasis en el siglo XIX de la mano de Kaan, de KraftEbing, de Westphal, de Lasègue, de Gorry, etc., las sexualidades del bebé y el niño, las del invertido y el fetichista, la de la relación médico-enfermo, las de la familia, etc., fueron el soporte y el efecto de un poder que las aisló, específico e intensificó, pues encontraba en ellas el instrumento para su generalización; un poder sobre el cuerpo y los placeres que tiende, como se ve, no a una prohibición condenatoria sino a una difusión simultánea de sí mismo y del objeto al que se dirige.

En este contexto fueron ubicados los Tres ensayos de Freud, y en particular la problematización de la sexualidad infantil alli desarrollada. Es decir que, siguiendo esta lectura, el poderío causal tan significativo asignado por Freud a la sexualidad infantil (lo cual estaba en linea con todos aquellos discursos que, desde la campaña anti-masturbatoria, venían alertando sobre 
sus peligros) y la comprobación de la determinación que ejercería sobre la constitución subjetiva, además de la especificación de su origen y naturaleza y del lugar ocupado por la familia en los mismos, toda esta productividad teórica habría estado en concordancia con los requerimientos expansivos de un poder que buscaba invadir la vida, la sexualidad, la subjetividad y el cuerpo de los individuos.

Así, los discursos y las instancias se diversificaron y multiplicaron al ritmo de, y como instrumentos para la expansión de un poder que no opera mediante el derecho sino mediante la técnica, no de acuerdo a la ley sino a la normalización, y que respondia al problema de la vida y la enfermedad. Los discursos no fueron sólo de ética sino también de racionalidad: el sexo no sólo se juzgó sino que fue objeto de análisis, de determinaciones causales, de cuantificaciones, de clasificaciones y especificaciones. Y las instancias de las que irradiaron estos discursos (la pedagogía, la medicina, la justicia penal, la demografia, la moral, la biología, la crítica política, y la denominada "función psi", en cuyo contexto el psicoanálisis ocupó un lugar privilegiado) se encargaron de erigir en torno al sexo la conciencia de un peligro y la apuesta a una verdad sobre uno mismo, todo lo cual volvía más acuciante la necesidad de hablar de él.

Vimos que el estatuto del psicoanálisis era, en rigor, paradójico pues reunió las exigencias proliferantes y productivas de la disciplina con los dictámenes conservativos y reproductivos de la ley prohibitiva. Para Foucault, en efecto, el psicoanálisis constituyó una interferencia en la sucesión de los regímenes de poder que caracterizaron a las sociedades soberanas y disciplinaras. La funcionalidad del psicoanálisis, y lo que explica su extraordinaria expansión en las sociedades occidentales, radicó, en la tesis de Foucault, en haber advertido los riesgos de la proliferación y en haberla recodificado en los términos de la ley. El psicoanálisis constituiría, en este sentido, el esfuerzo teórico por reinscribir la temática del sexo en el sistema de la ley, del orden simbólico y de la soberanía.

Pero no sólo la problematización freudiana de la sexualidad infantil resulta interesante en el contexto de estos problemas, sino también el lugar tan específico que Freud asignó a la familia en el proceso de constitución sexual. El psicoanálisis se encargó de determinar, por un lado, la naturaleza 
esencialmente parcial, perversa, múltiple y, por todo esto, profundamente amenazante del deseo, y de atenuar, por el otro, esa amenaza al establecer que al deseo sólo se accede en el marco familiar, por medio de la madreobjeto y del signo soberano del Padre. Se trató, de ese modo, para Deleuze y Guattari, de neutralizar la amenaza revolucionaria del deseo, y para Foucault, de atarla a los dictámenes de la ley. La familia permitió además acercar al cuerpo del niño un poder que, como vimos, necesita de una presencia constante y una estrecha proximidad fisica, y sirvió finalmente para la incitación (sexualización) y la prohibición (sofocación) del sexo, lo cual confirma el entramado complejo en el que se asienta, para Foucault, el denominado familiarismo del psicoanálisis: la familia aseguró a un tiempo la producción de la sexualidad y la reproducción de la ley.

La neutralización del deseo se llevaría a cabo, para Deleuze y Guattari, mediante una operación en la que se ponen en juego los problemas de la trascendencia y la representación. El inconsciente, para los autores, es una inmanencia productiva: mientras la producción es sometida al régimen de la representación (y vimos que el propio Freud hizo del inconsciente la sede de una serie de representaciones reprimidas), la inmanencia es convertida en trascendencia, lo cual inauguraba, para los autores, el problema del sentido y brindaba la posibilidad fundamental para el ejercicio de la hermenéutica psicoanalítica.

Al mismo tiempo, observamos que la teoría sexual de Freud no estaba exenta del régimen de lo normal-anormal, lo cual volvía a alinearla con el poder disciplinario. Pero esta constatación entraba en tensión con la evidencia, también expresada en la teoría de Freud, de la imposibilidad de emplear el criterio de normalidad en lo que respecta a la sexualidad. Aquí nuevamente la teoría de Freud reuniría exigencias opuestas: llevando en su cauce la exigencia de normalidad y la voluntad de normalización subjetiva, el discurso psicoanalítico no deja de manifestar la imposibilidad de toda norma y la torpeza que acompaña toda voluntad normalizadora.

Lo mismo sucede con la noción de origen. Derrida sostuvo que el concepto de análisis supuesto en la teoría de Freud no sólo es filolítico (tendiente a una descomposición permanente) sino también arqueológico (tendiente a la recaptura de un elemento originario, mínimo e indivisible). 
Freud da muestras, en efecto, de una voluntad arqueológica, de un análisis exhaustivo que pueda culminar en aquel último punto inanalizable; pero, al mismo tiempo, la teoría de Freud no deja de dar indicios de que esa voluntad de origen siempre está destinada a fracasar. Este punto es uno de los problemas introducidos por la noción de un inconsciente originario.

De cualquier modo, vale destacar la importancia de los discursos críticos que buscaron analizar la relación de la producción teórica psicoanalitica y su aparato técnico con el problema del poder y su articulación en los dispositivos de saber. Acá nos ocupamos de un recorte que sirve para exponer algunas de las ideas que contribuyeron a gestar el debate del que dio evidencias el pensamiento francés de la segunda mitad del siglo XX en las figuras no sólo de Foucault, de Deleuze y Guattari, de Derrida, y de Laplanche, sino también de Lacan, de Lyotard, de Althusser o de Castel. Estos debates han contribuido a cimentar una serie de polémicas que, en torno a ciertas preguntas fundamentales (¿es el psicoanálisis una práctica de alienación o de emancipación?, ¿cuál es la relación entre la ley y el deseo?, etc.), persisten hasta nuestros dias.

\section{Referencias bibliográficas}

Assoun, P-L. (1984). Freud y Nietzsche. México D.F.: Fondo de Cultura Económica.

Berenstein, I. (2008). Devenir otro con otro(s). Ajenidad, Presencia, Interferencia. Buenos Aires: Paidós.

Binswanger, L. (1981). La conception freudienne de $1^{\circ}$ homme a la lumiere de l'anthropologie" (La concepción freudiana del hombre a la luz de la antropologia). En Analyse existentielle et psychanalyse freudienne. Discours, parcours et Freud (Análisis existencial y psicoanálisis freudiano. Discurso, recorrido y Freud). París: Gallimard.

Cragnolini, M. (2002). Una ontología asediada por fantasmas: el juego de la memoria y la espera en Derrida. Escritos de filosofía, editada por la Academia Nacional de Ciencias, (41-42). Recuperado el 08/11/2014 en: 
$\underline{\text { http://www.jacquesderrida.com.ar/comentarios/ontologia_fantasmas.h }}$ $\underline{\operatorname{tm}}$

Deleuze, G., \& Guattari, F. (2006). Mil Mesetas: capitalismo y esquizofrenia. Trad. de José Vásquez Pérez. Valencia: Pre-textos.

Deleuze, G. \& Guattari, F. (2009). El Anti-Edipo: capitalismo y esquizofrenia. Trad. de Francisco Monge, Buenos Aires: Paidós.

Derrida, J. (2006). Resistencias del psicoanálisis. Trad. de Jorge Piatigorsky. Buenos Aires: Paidós.

Elias, N. (1994). El proceso de la civilización. Investigaciones sociogenétias y psicogenéticas. Trad. de Ramón García Cotarelo. México D.F.: Fondo de Cultura Económica.

Foucault, M. (2008). El poder psiquiátrico. Trad. de Horacio Pons. Buenos Aires: Fondo de Cultura Económica.

Foucault, M. (2010). Los anormales. Trad. de Horacio Pons. Buenos Aires: Fondo de Cultura Económica.

Foucault, M. (2013). Historia de la sexualidad, 1: La voluntad de saber. Trad. Ulises Guiñazú. Buenos Aires: Siglo Veintiuno Editores.

Freud, S. (1900/1986). "La interpretación de los sueños". En Obras Completas: vol. V. Trad. de José L. Etcheverry. Buenos Aires: Amorrortu.

Freud, S. (1905/2008). “Tres ensayos de teoría sexual”. En Obras completas: vol. VII. Trad. de José L. Etcheverry. Buenos Aires: Amorrortu.

Freud, S. (1910/2010). "Puntualizaciones psicoanaliticas sobre un caso de paranoia (Dementia paranoides) descrito autobiográficamente". En Obras completas: vol. XII. Trad. de José L. Etcheverry. Buenos Aires: Amorrortu.

Freud, S. (1950/2010). "Fragmentos de la correspondencia con Fliess (carta 69)”. En Obras completas: vol. I. Trad. de José L. Etcheverry. Buenos Aires: Amorrortu.

Lacan, J. (1996) El seminario. Libro 4: La relación de objeto. Buenos Aires: Paidós.

Lacan, J. (2009). El seminario. Libro I: Los escritos técnicos de Freud. Trad. de Rithée Cevasco y Vicente Mira Pascual. Buenos Aires: Paidós 
Laplanche, J. (1996). La prioridad del otro en psicoanálisis. Trad. de Silvia Bleichmar. Buenos Aires: Amorrortu. 